\title{
Thermal and mechanical analysis of the internal support for LNG cryogenic road tanker
}

\author{
Filip Lisowski ${ }^{1, *}$, and Edward Lisowski ${ }^{2}$ \\ ${ }^{1}$ Cracow University of Technology, Institute of Machine Design, al. Jana Pawła II 37, 31-864 Cracow, Poland \\ ${ }^{2}$ Cracow University of Technology, Institute of Applied Informatics, al. Jana Pawła II 37, 31-864 Cracow, Poland
}

\begin{abstract}
Road tankers for liquefied natural gas are designed as double-walled vacuum insulated tanks. The temperature difference between the fluid in the inner vessel and the environmental temperature can reach up to $200 \mathrm{~K}$. Supports holding the internal vessel must be able to transfer complex mechanical loads occurring under operating conditions and at the same time minimize the heat leakage to the tank. In this paper the construction of a steel support with a composite insert for a $25 \mathrm{~m}^{3}$ tank was considered. The proposed design was tested in thermal and mechanical finite element analysis using ANSYS software.
\end{abstract}

\section{Introduction}

The demand for natural gas has been growing in recent years. This is mainly due to sustainable development and energy security. Comparing to oil and coal, natural gas is the cleanest fossil fuel. Emissions of sulfur, nitrogen oxide and carbon dioxide from the combustion of natural gas are much lower than those for oil and coal. Natural gas can be transported by pipelines or liquefied as LNG using gas carriers or special cryogenic tanks [1]. Small and medium-sized stationary tanks as well as transport containers and road tankers are designed as doublewalled cryogenic tanks with vacuum insulation system. In previous publications, several authors focused on the design of LNG mobile tanks. In the paper [2] various materials on internal supports for mobile cryogenic container were considered. The numerical results of heat flux and temperature distribution for materials of low thermal conductivity like PTFE, textolite, polycarbonate or polyamide were compared.

In the paper [3] the results of study on using polyamide supports were discussed. The main goal of the paper was to experimentally determine the temperature distribution over time inside the polyamide supporting blocks under the constant pressure load. In the article [4] different types of LNG containers and referred problems of thermal analysis were discussed. In the paper [5] the design and thermal analysis of multilayered internal support were presented. The temperature distribution and average heat flux were determined for various number and dimension of steel layers under constant pressure. In the study the phenomenon of thermal contact resistance was taken into account. The papers [6-7] presents the results of numerical studies on thermal insulation systems for LNG road tankers. The authors of paper [8] presented the methodology of fatigue life calculations of LNG tank dedicated for carrier ship application. The calculations considered large range of loads and resulted in determining ship accelerations.

In this paper we propose the design of internal support consisted of stainless steel brackets and composite insert. The application in $25 \mathrm{~m}^{3}$ double-walled LNG road tanker was considered.

\section{Internal support design}

The design of the internal supports should provide high mechanical strength and in the same time low heat leakage to the tank. The condition of mechanical strength results in the largest possible cross-section of the support. On the other hand, a long heat transfer path and the small cross-section of the support are advantageous for a small thermal leakage. In addition, internal supports are located in the narrow annular space between the inner vessel and the outer jacket. The design of the inner supports must meet all of the above criteria. This can be achieved through a suitable geometric concept or by the use of low thermal conductivity materials. Double-walled tanks of road tankers have usually such an internal support system as at least two supports are fixed and the others are sliding. Fixed supports are intended to keep the inner tank constant in relation to the outer jacket and to limit longitudinal displacements. The sliding supports, on the other hand, are intended to allow a thermal shrinkage but at the same time to block radial displacements.

Accepting the design loads for mobile tank, the following static loads must be taken into account in accordance with the EN 13530-2:2002 standard [9]:

(1) In the direction of travel: twice the total mass.

(2) Perpendicular to the direction of travel: total mass.

(3) Vertically upwards: total mass.

(4) Vertically downwards: twice the total mass.

\footnotetext{
* Corresponding author: filip.lisowski@mech.pk.edu.pl
} 
In the following study the fixed support of the $25 \mathrm{~m}^{3}$ tank was considered. The concept of the support design included a cylindrical joint consisted of stainless steel brackets and the insulating insert made of Durolight S2 ${ }^{\circledR}$ composite is shown in the Fig. 1.

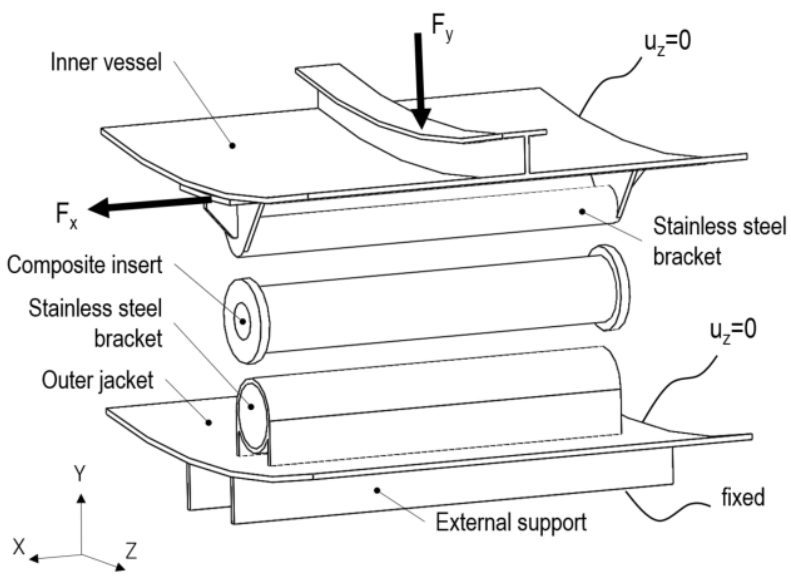

Fig. 1. Boundary conditions and loads for mechanical analysis $\left(\mathrm{u}_{\mathrm{z}}=0-\right.$ around all edges $)$

\section{Material data}

It was assumed that the inner tank, the outer jacket, steel brackets of the internal support and the external support are made of stainless steel 1.4311 with mechanical properties summarized in the table 1 and thermal conductivity shown in the Fig. 2. Mechanical and thermal properties of composite material Durolight $\mathrm{S} 2{ }^{\circledR}$ are summarized in the table 2 .

Table 1. Mechanical Properties of Stainless Steel 1.4311

\begin{tabular}{|c|r|}
\hline Properties of stainless steel 1.4311 & Value \\
\hline Yield strength & $270 \mathrm{MPa}$ \\
\hline Modulus of elasticity & $210 \mathrm{GPa}$ \\
\hline Poisson ratio & 0,28 \\
\hline
\end{tabular}

Table 2. Mechanical Properties of Durolight $S 2^{\circledR}$

\begin{tabular}{|l|r|}
\hline Properties & Value \\
\hline Flexural strength $\perp$ & $350 \mathrm{MPa}$ \\
\hline Modulus of elasticity in flexion $\perp$ & $18000 \mathrm{MPa}$ \\
\hline Compressive strength $\perp$ & $450 \mathrm{MPa}$ \\
\hline Tensile strength $\mid$ & $180 \mathrm{MPa}$ \\
\hline Thermal conductivity & $0,3 \mathrm{~W} / \mathrm{mK}$ \\
\hline|| - parallel to the lamination & X direction \\
\hline$\perp$ - perpendicular to the lamination & Y direction \\
\hline
\end{tabular}

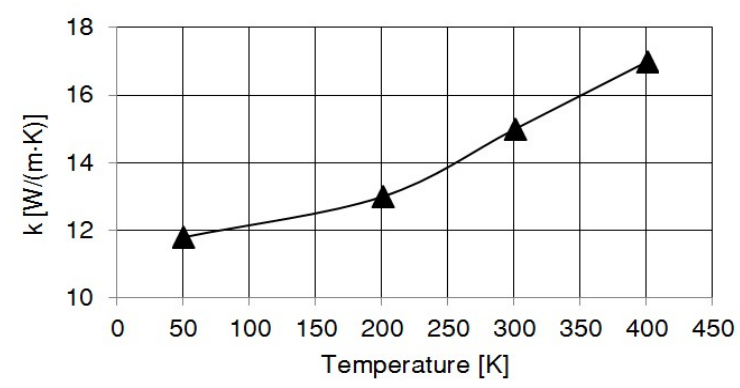

Fig. 2 Thermal conductivity of steel 1.4311 [10]

\section{Finite element analysis}

The analysis considered $500 \times 500 \mathrm{~mm}$ section of the tank with dimensions given in table 3 . Static mechanical analysis and transient thermal analysis were carried out separately. 4-node shell elements were accepted for steel elements and 20-node solid elements for the composite insert. The converged mesh obtained for mechanical and thermal analysis is shown in the Fig. 3 and Fig. 4.

\subsection{Assumptions for mechanical analysis:}

- The model is fixed and loaded as shown in the Fig. 1

- Values of loads $F_{x}=105 \mathrm{kN}$ and $F_{y}=26 \mathrm{kN}$ are accepted in accordance with the standard [9], assuming density of LNG equal to $450 \mathrm{~kg} / \mathrm{m}^{3}$.

- The tank has four bottom supports located symmetrically to the longitudinal axis of the vehicle and two of them are fixed.

- $\mathrm{F}_{\mathrm{z}}=0$, under the assumption, that all loads in $\mathrm{Z}$ direction are transferred by side supports that are not considered in current analysis.

- A frictional contact with a friction coefficient of 0,1 was defined between the insert and brackets

\subsection{Assumptions for thermal analysis:}

- The model is in a state of thermal equilibrium, which is obtained after 24 hours.

- The initial temperature in analysis is $20^{\circ} \mathrm{C}$.

- The temperature of internal tank is $-160^{\circ} \mathrm{C}$

- The external surface of tank jacket exchanges heat with environment by convection with accepted convection coefficient $8,89 \mathrm{~W} /\left(\mathrm{m}^{2} \mathrm{~K}\right)$ at $20^{\circ} \mathrm{C}$ [5],

- Heat is transferred through the internal support only by the conduction.

- Thermal contact resistance is omitted due to the high pressure acting on the support.

Table 3. Dimensions of the $25 \mathrm{~m}^{3} \mathrm{LNG}$ tank and the support

\begin{tabular}{|l|r|}
\hline Dimension name & Value \\
\hline Outer diameter of the inner tank & $2200 \mathrm{~mm}$ \\
\hline Outer diameter of the outer jacket & $2412 \mathrm{~mm}$ \\
\hline Wall thickness of the inner tank & $6 \mathrm{~mm}$ \\
\hline Wall thickness of the outer jacket & $6 \mathrm{~mm}$ \\
\hline Width of the internal support & $200 \mathrm{~mm}$ \\
\hline Length of the internal support & $500 \mathrm{~mm}$ \\
\hline
\end{tabular}

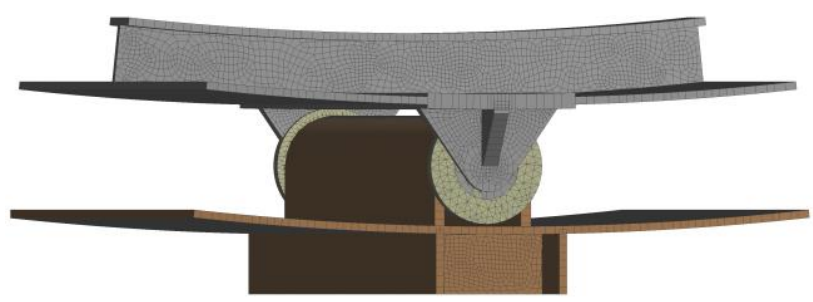

Fig. 3. Mesh for mechanical analysis 


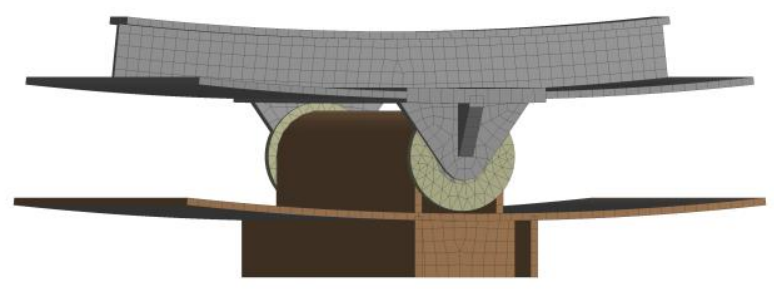

Fig. 4. Mesh for thermal analysis

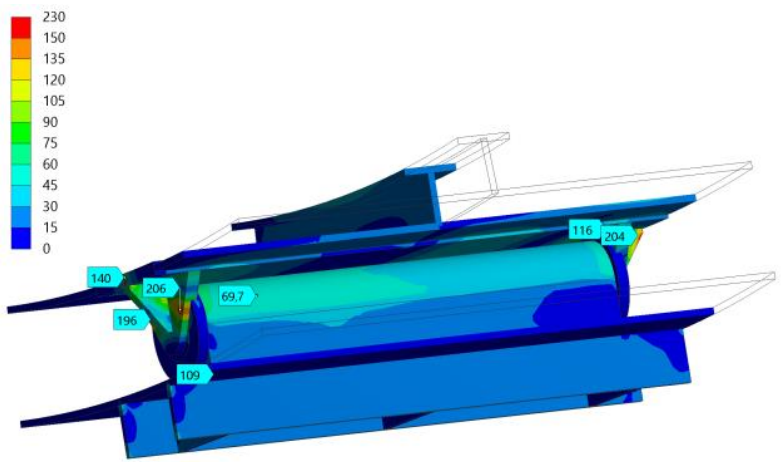

Fig. 4. Von Mises equivalent stress $\sigma_{\max }=206 \mathrm{MPa}$ (for stainless steel elements)

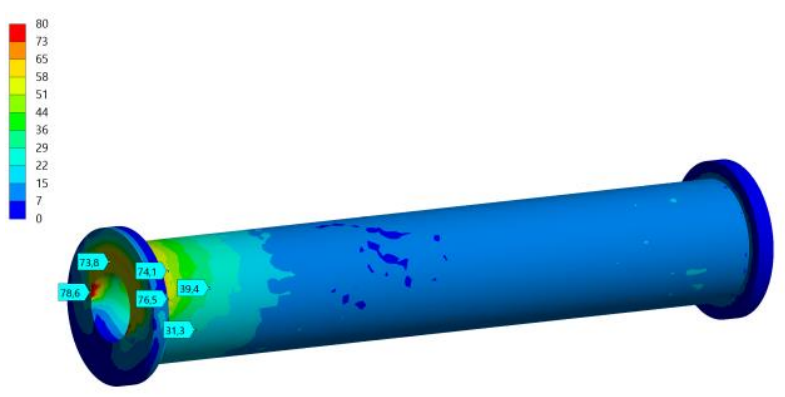

Fig. 5. Von Mises equivalent stress $\sigma_{\max }=79 \mathrm{MPa}$ composite insert

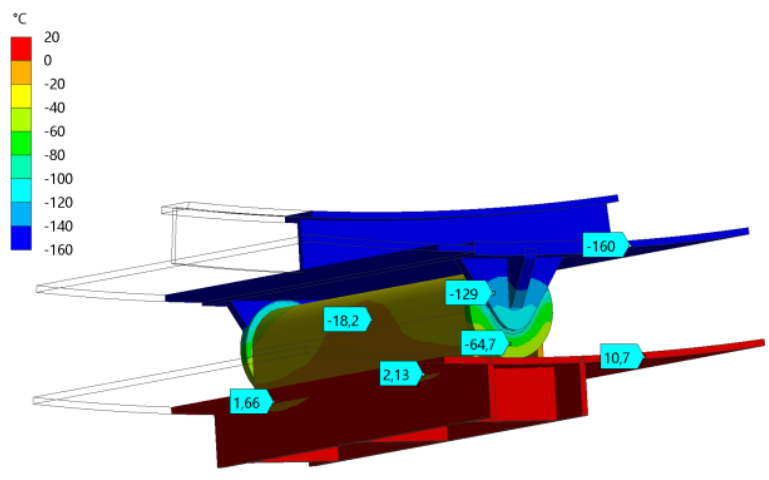

Fig. 6. Temperature distribution

\subsection{Results of mechanical analysis}

Results of the static mechanical analysis are presented as distributions of von Mises equivalent stress. Fig.4 presents the result for the whole analyzed structure, while Fig. 5 presents the results for composite insert.
Maximum Von Mises equivalent stress within steel elements is equal to $206 \mathrm{MPa}$ and is below the yield strength. For the composite insert, the maximum reduced stress is equal to $79 \mathrm{MPa}$ and occurs on the edge of the inner hole. The region with stress concentration is under the tensile stress in Y direction, which in line with the previous assumption (table 2) is perpendicular to the composite lamination. The calculated tensile stress is therefore less than the permissible value. In the area of stress concentration on the outer cylindrical surface, the composite insert is compressed and bent. However, the peak stresses in this area are also less than the allowable compression and bending stresses for the accepted material.

\subsection{Results of thermal analysis}

As a result of transient thermal analysis the distributions of temperature shown in the Fig. 6 was obtained. It can be noticed that the temperature at the tank jacket is above zero. This is advantageous because the frost will not accumulate on the tank surface. The heat leakage through the internal support equal $36 \mathrm{~W}$ was also determined for the design under analysis.

\section{Summary}

The concept of internal support for application in $25 \mathrm{~m}^{3}$ LNG double-walled road tanker was proposed. The support consisted of steel brackets and composite insert. Due to the way the elements are connected, the support is a cylindrical joint. Such a joint may be beneficial in order to compensate displacements caused by the thermal shrinkage and the mass of liquid.

Proposed design of the support was tested by applying thermal and mechanical finite element analysis. In the continuing research, other support concepts will be proposed and compared with current results.

\section{References}

1. W. Ikealumba, and $\mathrm{Wu}, \mathrm{H}$, (2014), Some recent advances in liquefied natural gas (LNG) production, spill, dispersion, and safety, Energy Fuels, 28, pp.3556-3586.

2. Lisowski, E, Czyżycki, W, and Łazarczyk, K, (2010), Simulation and experimental research of internal supports in mobile cryogenic tanks, Technical Transactions, Mechanics, 2-M, pp.175-184.

3. Lisowski E, Czyżycki, W, and Łazarczyk, K, (2010), Using of polyamide in construction of supporting blocks of cryogenic tanks on example of LNG container, Archives of Foundry Engineering, vol.10, Special Issue 3/2010.

4. Lisowski, E, and Czyżycki, W, Transport and storage of LNG in container tanks, (2011), Journal of KONES Powertrain and Transport, vol.18, No.3, pp.193-201. 
5. Czyżycki, W, (2015), Modeling of heat flow through multilayer internal supports of cryogenic vessels, Technical Transactions, Mechanics, 2-M, pp.27-34.

6. Lisowski, E, and Lisowski, F, (2019), Influence of vacuum level on insulation thermal performance for LNG cryogenic road tankers, MATEC Web of Conferences 240, 01019, ICCHMT 2018, https://doi.org/10.1051/matecconf/20182400101

7. Lisowski, E, and Lisowski, F, (2019), Study on Thermal Insulation of liquefied natural gas cryogenic road tanker, Thermal Science, Vol. 23, Suppl. 4, pp.S1381-S13911.

8. Skrzypacz, J, and Jaszak, P, (2018), Selected aspects of cryogenic tank fatigue calculations for offshore application, Int. J. of Applied Mechanics and Engineering, vol. 23, No.1, pp.251-259, DOI: 10.1515/ijame-2018-0015

9. EN 13530-2:2002. Cryogenic vessels - Large transportable vacuum insulated vessels.

10. Czyżycki, W, (2011), Heat flow modelling on thermal insulation of cryogenics tanks using SolidWorks Simulation package, Technical Transactions, Mechanics, 4-M, pp.29-36. 